INTERVIEW

$\Lambda^{t}$ t the TA18 conference on "Technology Assessment and Normativity", held in Vienna in June 2018, an equally spontaneous and memorable controversy arose between Armin Grunwald and Pierre Delvenne concerning the roles of neutrality and democracy in technology assessment (TA), its philosophical foundations, and TA's obligation to be inclusive. How do TA's obligation to democracy and its operational neutrality relate to each other, where do they interfere, and what are the practical consequences? And what does this imply for TA's future? Should we shape TA today according to the ideals of a strong democracy that advocates value-oriented solutions while not shying away from conflicts? Or should we rather strive for a fundamental normative orientation toward democracy, which, however, for this very reason follows the neutrality principle in TA practice and does not favor certain pathways? As editors of TATuP's special issue on normativity in technology assessment, our intention has been to make this debate accessible to a wider readership by confronting the two researchers once more with the core issues of their dispute. Interview by Linda Nierling (ITAS, KIT) and Helge Torgersen (ITA, Vienna).

Interviewers: Armin Grunwald and Pierre Delvenne, in how far can technology assessment take a neutral role with regard to its core task of creating and assembling sound knowledge as a basis for policy advice?

Armin Grunwald: On the one hand, I agree that TA has a normative fundament in favor of - in particular deliberative democracy and that, with respect to this fundament, it is not neutral - besides the fact that there is probably no neutral agent on this planet at all. However, at the dimension and level of specific technologies under consideration, fulfilling TA's mission according to this fundament requires neutrality or unbiasedness, respectively. Hence, the notion of neutrality must be considered in a more differentia-

This is an article distributed under the terms of the Creative Commons Attribution License CCBY 4.0 (https://creativecommons.org/licenses/by/4.0/) https://doi.org/10.14512/tatup.28.1.71

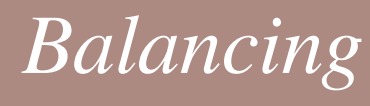

engagement

and

neutrality in technology

assessment

Should technology

assessment take a

stance - when, on what,

and how? How to deal

with its neutrality para-

digm in times of anti-

democratic tendencies?

ted way, at least at the two levels of (a) debates over the political regime and (b) debates on new technology. This differentiated view on neutrality does not hinder TA to be transformative.

Pierre Delvenne: I cannot agree more regarding the absence of a neutral agent. In the same vein, I do not think that neutrality at the dimension of technologies is possible. This is because TA practices and scientific standards are associated with political preferences and specific values that hinder the possibility of a totally neutral treatment. Not only are TA's rationales and normativities committed to general ideals such as empowe- ring publics or enlightening policy. Also, TA practices support particular visions of the world: both how it is and how it ought to be, for instance, with regard to greater epistemic and social inclusiveness. In such a perspective, I do not think that technologies and the political context in which they take place can be separated. Furthermore, and following Sheila Jasanoff, I consider that technologies and political contexts are deeply co-produced. This implies that the ways in which we know and represent the world (including specific technologies) are inseparable from the ways in which we choose to live in it. If TA wants to fully acknowledge and exert its transformative role, it needs to take this mutual shaping seriously into account, both for a fine-grained understanding of the technologies to be assessed that do not emerge in a political vacuum, and to achieve a meaningful impact on policy making.

Interviewers: TA is often said to have a role in democratic decision making. But what exactly is the significance of democracy for TA and vice versa: what is the role of TA within different democratic settings? Would you think that TA could also serve policy in another system that may be less democratic?

Grunwald: In general, I postulate that TA is heavily obliged to democracy. History clearly supports this: Take the story of the US-American Office for Technology Assessment, which shows that TA originated at the core of parliamentary democracy. Then, there is the history of 50 years of TA serving parliaments as the institutional hearts of democracy. Finally, there is the history of TA postulating, supporting, and practicing participatory and deliberative democracy - all these TA practices support my postulate and Pierre's claim alike. Furthermore, this history, and the status reached so far, allows concluding that TA is obliged to democracy not only in general but also to a specific type, namely the "strong" democracy of Benjamin Barber, or the "deliberative" democracy of Jürgen Habermas, Frank Fischer, and others. This, however, 
is "only" an argument derived from history and practice. Theoretically, TA's relation to democracy could be subject to contingent circumstances, and TA could completely change its nature over the years to come. For example, TA could be hijacked by populist movements or even dictators. Yet, would it still be TA if a dictator used TA methods and concepts

\section{Technologies and the}

\section{political context in}

\section{which they take place}

\section{cannot be separated,}

\section{rather they are deeply co-produced.}

for supporting his or her dictatorship and to suppress people? In this case, the reference to former times, when TA was democratic by its nature, might become a historic reminiscence only.

Delvenne: I agree with Armin on TA's democratic obligation or commitment, which is related to TA's history and practice. And I deeply share the concern of TA becoming either the target of populist, extremist, "post-truth", or racist politicians or of TA becoming an institution led to serve disreputable policy goals. But the point I like to defend, as elaborated together with Céline Parotte, is that TA institutions and practitioners are not merely passive instruments in the hands of the powerful. Rather, they possess agency that they can and must exert. Thus, it is up to them to anticipate the consequences of ongoing political changes, for example, by asking themselves three simple questions:

1. Are TA practitioners ready to serve a new class of suspicious addressees in the exact same way as they have been devoting their expertise to policy making in the past?

2. Are they even able to be of service to such policy purposes, given the obvi- ous divergences with TA's epistemologies?

3. Are TA practitioners willing to uncritically go down the path of any contemporary politics?

Obviously, if asked, I would bluntly answer NO to all three questions. But there may be divergent or more nuanced opinions. In the end, it is up to the individual

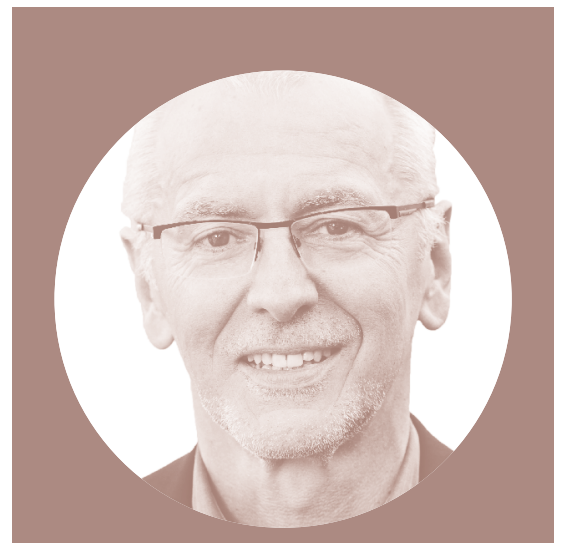

\section{Armin Grunwald}

is a physicist and philosopher. He is

head of the Institute for Technology

Assessment and Systems Analysis

(ITAS) at Karlsruhe Institute of

Technology (KIT) and director of the

Office of Technology Assessment at

the German Bundestag (TAB).

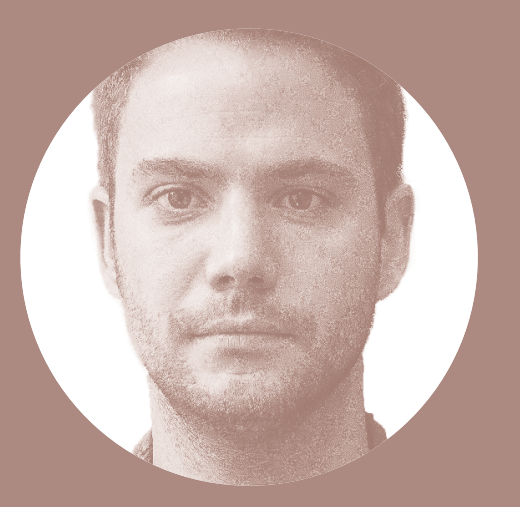

Pierre Delvenne

is a political scientist from the

University of Liège. He is the associate

director of SPIRAL, a multidisciplinary

research center involved in setting up

an Office of Technology Assessment at

the Wallonian Parliament.
TA practitioners to respond, and their responses will provide TA communities with crucial indications on how, where, and in which direction to exert their agency.

Regarding historic reminiscence, TA practices will always evolve, just like the context in which they unfold. However, TA's historical obligation to democracy cannot be buried or forgotten; rather, I see it as a compass both for understanding past TA practices and for designing those to come. If TA became endangered, for example, if democracy gets under the attack of populist movements or dictators who consider TA to be part of the "establishment" they want to get rid of or to "misrepresent the real people", TA's particular history and set of practices should be actively remembered and possibly defended. Thus, in such troubled times, TA must become a bastion of democratic politics. In my view, defending democracy and knowledge-based policy making is as much a moral duty as a survival strategy, because the political habitat of TA is democracy and TA practices can only unfold in a democracy that is alive and inhabited by pluralism.

Interviewers: Is TA's strong obligation to democracy just a historical contingency or is it theoretically rooted in normative and philosophical foundations and if so, how?

Grunwald: In fact, TA's philosophical foundations provide a stronger argument for its democratic orientation than the mere reference to TA's history. The TA practices we have seen in history, as well as those we see today, are deeply rooted in theoretical considerations that are not only historically contingent but also have strong traditions behind them. The very idea of TA originates in the political philosophies of John Dewey and Jürgen Habermas, going back to ideas of Immanuel Kant and others. Hence, not only history and the current status of TA supports Pierre's conclusion that TA is not neutral at the level of the political regime. Rather, TA is obliged to democracy due to its normative and philosophical roots. This already implies that TA cannot stay neut- 
ral in case democracy comes under pressure. In this respect, TA must be, in the terminology of Roger F. Pielke, an issue advocate in favor of democracy.

Delvenne: Well, I think that Pielke's terminology and idealized roles may be nice as a theoretical concept but are intrinsically problematic in practice. Anyway, the philosophical foundations Armin mentioned are indeed the traditional roots of TA. As such, they forcefully influenced its ontology and evolving practices. While I acknowledge these foundations as evident and important, which a rich literature supports, I think they are not sufficient to deal with contemporary politics. Rather, TA communities need to look for additional philosophical resources. In the article with Céline Parotte mentioned, we suggest that Chantal Mouffe's theory of pluralistic agonism may be a welcome addition to TA's philosophical library. It provides powerful resources for TA to invent its own politics, rendering more explicit the political normativities and values that underlie its actions and projects. Unlike Habermas, Mouffe considers conflict not only to be legitimate but also to guarantee that democracy is alive and inhabited by pluralism. As Van Bouwel and Van Oudheusden stressed, this move marks a clear difference vis-à-vis deliberative democracy theorists in terms of the "meta-consensus" in democratic models, for example, regarding the way deliberative reasoning and (social) rationality should be understood and invoked. In other words, the deliberative theorists' meta-consensus postulates that, in principle, dissent can and should be resolved through deliberation and rational discussion. In contrast, Mouffe's meta-consensus is conflictual; it implies an agreement on the impossibility to conclusively come to terms with dissent. In addition, according to Mouffe, we should not attempt to definitively resolve dissent on the meta-level as doing so would oppose the very meaning of democratic pluralism.

Grunwald: I do not share Pierre's interpretation of Habermas' model of democracy. It is a widespread misunderstan- ding in the political sciences that, in this model, the existence of conflicts would be regarded as a kind of deficit to be overcome. Rather, the (philosophical) idea behind is only that a real consensus is the only way to completely avoid violence. Therefore, consensus is nothing more than a kind of regulative idea or counterfactual utopia. And even if consensus could really be achieved regarding a particular issue, it immediately would be challenged in dealing with the next upcoming issue. Conflicts are the motor of democracy, here I agree with Pierre.

Interviewers: If conflicts are the motor of democracy, how can TA fulfil its mission to serve democracy without getting involved in the conflicts itself?

Grunwald: Here I would like to emphasize inclusion as another important conceptual aspect. In fulfilling its mission based on the normative fundament of deliberative democracy, TA has to observe specific values and to consider specific conceptual dimensions. According to this normative fundament, inclusion is such a major value-laden dimension. TA needs the concert of opinions, or should it stay away from taking sides?

Grunwald: The obligation of inclusion has important consequences indeed. Coming back to the question of neutrality, namely, it implies that TA cannot be an issue advocate with regard to specific technologies, to particular dimensions of their consequences, or to specific norms and values to be applied for assessing them. Rather, TA has to stick to the role of the "honest broker" in Pielke's terminology. This role does not exhaust in acting as a neutral moderator in equidistance to the positions and perspectives of the actors and stakeholders involved, as some might suggest. In contrast, TA should take a clear standpoint in the respective public and political debate. However, it should only do so if this standpoint is based on the results of a TA process that is organized according to all of TA's ideals and quality criteria (such as inclusion), and if the outcome of this process is a clear result, which prioritizes one specific technology over alternative options for example, in the transformation of the energy system. TA would, in such an in-

\section{Technology assessment is obliged to democracy due to its normative and philosophical roots.}

to assess technology and its possible consequences not only from the perspective of the decision makers. Rather, TA has to take into account the possibly diverse and diverging social perspectives and different pieces of knowledge supplied by different actors such as stakeholders, citizens, and people affected, including future generations. Hence, inclusion has two sides: TA has to be inclusive in epistemic as well as in social respects.

\section{Delvenne: I fully agree.}

Interviewers: But doesn't the inclusion of many views and pieces of knowledge make things even more complicated? And should TA define its stance among stance, not act as an issue advocate in the same way as a pressure group or lobbyist would do.

Delvenne: Why can TA not be an issue advocate on technologies? I argue that TA cannot be, at the same time, both engaged in defending and preserving democracy as an issue advocate and pretending to be an "honest broker" when it comes to choices between technologies that, as we know, are inherently (non-)democratic and deeply value-laden. In fact, TA is so deeply engaged in, and obliged to, democracy that it cannot pretend that its rooted normative advocacy may vanish at the level of its practices. Armin seems to claim that it is both possible and desirable to 
mark the difference between TA as an issue advocate for democracy, on the one hand, and as an "honest broker" regarding specific technologies on the other.

Grunwald: TA relies on the results of its own assessments that are performed in accordance with its standards, which are based on normative ideals such as strong democracy and other common good-oriented issues. In turn, the ideals build on TA's obligation to inclusion in a social as well as epistemic respect. The "honest broker" is allowed to follow good (such as zero carbon, socially just, redistributive, knowledge- or labor-intensive societies) at the expense of other directions that, at least implicitly, should be avoided, such as societies that are extremely polarized, technophobic, or distrustful of evidence or of policy making.

Interviewers: From the discussion so far, it is evident that your respective positions both overlap and diverge. In summary, where do you see commonalities and where do you spot major differences? be attuned to the situated political context and the civic epistemology in which each TA institute operates, my view is that TA needs, in addition to John Dewey's or Jürgen Habermas' concepts, other philosophical resources such as Chantal Mouffe's pluralistic agonism.

Grunwald: To conclude, Pierre and I seem to share many positions with regard to TA's basic obligation to democracy and the role it has in serving and defending it. I think we agree on TA being an instrument in and for democratic rea-

\section{The obligation of inclusion implies that technology assessment} cannot be an issue advocate with regard to specific technologies, or to specific norms and values to be applied for assessing them.

arguments - but what is to be regarded as "good" is related to the quality of the TA process according to its normative roots. Following good arguments, in this sense, and representing positions and conclusions based on them is categorically different from being in favor of specific technologies due to partisan interests or stakes like an issue advocate would be.

Delvenne: I think that picturing TA as being torn apart between normativity and neutrality would be a rather unproductive window dressing. First, this incoherence may be one of the reasons why it is sometimes hard to explain what TA is, what it does, and what it stands for beyond the
Delvenne: I fully agree that TA cannot stay neutral if democracy comes under pressure. And we probably also agree on the fact that democracy today, in Europe and elsewhere in the world, comes under increasing pressure. Thus, we may even agree that, given this worrisome situation, TA's "neutrality myth" has to be reconsidered and a politics of TA needs to be invented. Where I see us bifurcate is on the significance of neutrality. Armin still seems attached to a certain level of - in my view mythical - neutrality that could still be preserved somehow and that would even be necessary. I think TA is never neutral, not regarding its foundations and neither at the level of specific techno- soning and decision making on technologies, based on values and ideas of a "strong democracy" that must be defended if coming under pressure. However, it is exactly this obligation that calls for inclusiveness and this, in turn, entails not taking an open stance on the level of material questions, for example, whether to favor this or that interest over any other. Rather, this obligation demands relying on the results of a TA process carried out according to the fundamental values inherent in the normative core of TA.

\section{Technology assessment is never neutral, not regarding its foundations and neither at the level of specific technologies.}

circle of TA communities. Second, it may be argued that TA is always acting as an issue advocate in practice. After all, it shapes normative visions of technological futures favoring particular directions logies. A quick look at the actual way how TA frames technological issues and at the actual themes and conclusions of TA reports may support this claim. Regarding how to invent a politics of TA that would 